Research

Open Access

\title{
Glutamine induces heat-shock protein and protects against Escherichia coli lipopolysaccharide-induced vascular hyporeactivity in rats
}

\author{
Liang Jing, Qiong Wu and Fuzhou Wang
}

\author{
Department of Anesthesiology, Zhongda Hospital and School of Clinical Medicine, Southeast University, 87\# Ding Jia Qiao Rd., Nanjing, Jiangsu, \\ China \\ Corresponding author: Liang Jing, jinglg@gmail.com
}

Received: 6 Dec 2006 Revisions requested: 16 Jan 2007 Revisions received: 3 Feb 2007 Accepted: 9 Mar 2007 Published: 9 Mar 2007

Critical Care 2007, 11:R34 (doi:10.1186/cc5717)

This article is online at: http://ccforum.com/content/11/2/R34

(c) 2007 Jing et al.; licensee BioMed Central Ltd.

This is an open access article distributed under the terms of the Creative Commons Attribution License (http://creativecommons.org/licenses/by/2.0), which permits unrestricted use, distribution, and reproduction in any medium, provided the original work is properly cited.

\begin{abstract}
Introduction Vascular hyporeactivity is an important problem associated with sepsis. Although the mechanism involves inflammatory pathway activation, specific therapeutic approaches have not been defined. Glutamine (GIn) has been shown to provide some anti-inflammatory effects and improve outcomes in sepsis. Here, we tested the hypothesis that Gln could reduce Escherichia coli lipopolysaccharide (LPS)induced vascular hyporeactivity and evaluated the role of heatshock protein 70 (HSP70) induction in this process.

Methods Twenty-four male Sprague-Dawley rats were divided into control, LPS shock, and alanyl-GIn dipeptide+LPS shock (Ala-Gln+LPS) groups. Six hours after administration of LPS, phenylephrine (PE) (0.5 to approximately $2.5 \mu \mathrm{g} / \mathrm{kg}$ ) was applied intravenously to all groups, and the percentage increase in mean arterial pressure (MAP) was detected in the respective groups. The concentration-response curve of PE was obtained in tension experiments, and the average values of $P E$ maximum efficacy $\left(E_{\max }\right)$ and median effective dose $\left(E C_{50}\right)$ were calculated. The plasma concentrations of malondialdehyde (MDA), tumor necrosis factor-alpha (TNF- $\alpha$ ), and interleukin-6

(IL-6) were detected in all groups. The expressions of HSP70 from heart, liver, lung, and aorta were also assayed in all groups.

Results The maximal percentage increase in MAP induced by PE was significantly reduced to $12.7 \%$ in the LPS shock group $(P<0.05)$ and was restored to $15.6 \%$ in the Ala-Gln+LPS group $(P<0.05)$, whereas the control group was $24.7 \%$. The average values of $P E E_{\max }$ and $E C_{50}$ were significantly impaired in the LPS shock group $(P<0.05)$ but partially restored in the Ala-GIn+LPS group $(P<0.05)$. The expressions of HSP70 from the heart, aorta, lung, and liver were much higher in the AlaGln+LPS group than those in the LPS shock group $(P<0.05)$. The plasma concentrations of TNF- $\alpha, \mathrm{IL}-6$, and MDA were much lower in the Ala-GIn+LPS group than those in the LPS shock group.

Conclusion Gln effectively improves vascular reactivity by inducing the expression of HSP70, reducing inflammatory cytokine release and peroxide biosynthesis in LPS shock rats. These results suggest that Gln has a potentially beneficial therapeutic effect for septic shock patients.
\end{abstract}

\section{Introduction}

Septic shock is a complex pathophysiological state, and despite considerable therapeutic advances, it remains a major therapeutic challenge with a high incidence of mortality [1]. Vascular hyporeactivity to catecholamine vasoconstrictors is a characteristic feature of septic shock, plays a key role in this pathological process, and results in arterial hypotension, multiple organ dysfunction, and death. The underlying mechanism of impaired vasopressor responsiveness in septic shock is not completely understood but likely involves the activation of inflammatory pathways [2].

The therapeutic approaches for the treatment of vascular hyporeactivity in septic shock have included using high-dose vasoactive agents, nitric oxide synthases inhibitors [3], guanylate cyclase inhibitor [4], low-dose corticosteroids [5], and

Ala-GIn+LPS = alanyl-glutamine dipeptide + lipopolysaccharide shock; $\mathrm{EC}_{50}=$ median effective dose; $\mathrm{E}_{\mathrm{max}}=$ maximum efficacy; $\mathrm{Gln}_{\mathrm{I}}=$ glutamine; $\mathrm{HSP}=$ heat-shock protein; HSP70 = heat-shock protein 70; IL-6 = interleukin-6; LPS = lipopolysaccharide; LR = lactated Ringer's solution; MAP = mean arterial pressure; MDA = malondialdehyde; $P E=$ phenylephrine; TNF- $\alpha=$ tumor necrosis factor-alpha. 
antioxidant therapy [6]. These have been experimentally used in clinical and animal studies, but their value in therapeutics is not proven. Thus, the precise mechanisms of cardiovascular dysfunction during sepsis warrant further study and the new therapeutic approaches should be explored.

Heat-shock proteins (HSPs) are self-protective proteins that maintain cell homeostasis against various forms of stress as an adaptive response [7]. These proteins are induced by a wide variety of stressors and have broad cytoprotective functions. The 70-kDa family of HSP (HSP70), in particular, plays a vital role in cellular protection and has been detected in various tissues subject to stress $[8,9]$. Heat stress, gene transfer, and some small-molecule agents have been reported to induce HSP70 expression [10-12], but the potential clinical value of these approaches has not been defined.

Glutamine (GIn), a non-essential amino acid, has been demonstrated to attenuate pro-inflammatory cytokine release [13] and lung metabolic dysfunction in animal models of endotoxin shock through enhanced HSP expression [14]. No previous studies have evaluated the impact of Gln administration on sepsis-related vascular hyporeactivity. In this study, we examined the hypothesis that pretreatment of Gln could induce HSP70 expression and improve vascular reactivity in a relevant rat model of lipopolysaccharide (LPS)-induced sepsis.

\section{Materials and methods Animals}

The study was approved by the Ethical Committee of Animal Research at the College of Medicine, Southeast University, Nanjing, China. Twenty-four healthy male Sprague-Dawley rats weighing 250 to approximately $300 \mathrm{~g}$ were randomly divided into three groups: a control group, which received an intravenous infusion of 5 to $7 \mathrm{ml}$ of lactated Ringer's solution (LR) $(n=8)$; an LPS shock group, which received an intravenous infusion of 5 to $7 \mathrm{ml}$ of LR until one hour before intravenous administration of LPS (Sigma-Aldrich, St. Louis, MO, USA) $10 \mathrm{mg} / \mathrm{kg}(n=8)$; and an alanyl-Gln dipeptide+LPS shock (Ala-Gln+LPS) group, which received an intravenous infusion of 5 to $7 \mathrm{ml}$ of $4 \%$ Ala-Gln until one hour before intravenous administration of LPS $(n=8)$. All fluids were infused by micropump at a rate of 5 to $7 \mathrm{ml} /$ hour.

\section{Glutamine administration}

Gln was administered as 20\% Ala-Gln (Fresenius Kabi Austria $\mathrm{GmbH}, \mathrm{Graz}$, Austria), which was diluted into 4\% solution with LR for intravenous infusion because Ala-Gln must be diluted five times for intravenous administration in clinical application. Five to seven milliliters of $4 \%$ Ala-GIn was administered to yield $0.75 \mathrm{~g} / \mathrm{kg}$ per dose of Gln. Ala-Gln solution or LR vehicle was administered via femoral vein injection.

\section{Measurement of mean arterial pressure}

All rats were anesthetized with sodium pentobarbital $(40 \mathrm{mg} /$ $\mathrm{kg}$ intraperitoneally), and a supplemental dose $(20 \mathrm{mg} / \mathrm{kg}$ ) was added if necessary. The rats were allowed to keep breathing spontaneously. One catheter was placed in the femoral artery and connected to the pressure transducers for recording mean arterial pressure (MAP), and another one was placed in the femoral vein as a route for drug administration. MAP values of the rats were decreased after administration of LPS in the LPS group and the Ala-GIn+LPS group, and an MAP decrease of $25 \%$ to $30 \%$ of baseline level was regarded as endotoxin shock [15]. Six hours after administration of LPS, phenylephrine (PE) (Shanghai Harvest Pharmaceutical Co., Ltd., Shanghai, China) in doses of $0.5,1.0,2.0$, and $2.5 \mu \mathrm{g} / \mathrm{kg}$ was applied every 20 minutes via the femoral vein; the percentage increase in MAP was recorded in each group.

\section{Isolated vascular function}

All rats were anesthetized by sodium pentobarbital and killed by decapitation after levels of MAP were measured. The thoracic aorta was rapidly isolated and prepared with the endothelium intact. Vascular segments ( 3 to $4 \mathrm{~mm}$ ) were suspended by stainless steel hooks in 10-ml tissue baths containing Krebs buffer at $37^{\circ} \mathrm{C}$, oxygenated by constant bubbling of a $95 \% / 5 \% \quad \mathrm{O}_{2} / \mathrm{CO}_{2}$ mixture, and incubated for 90 minutes. Tension data were collected with the Biologic Signal Collecting System (Nanjing Medical University, Nanjing, China). After five washes, concentration effect data were obtained by cumulative addition of PE $\left(1 \times 10^{-9}\right.$ to $1 \times 10^{-4} \mathrm{M}$; SigmaAldrich).

\section{HSP70 protein expression detection with Western blotting analysis}

Six hours after injection of LPS, the heart, liver, lung, and aorta were harvested, immediately frozen in liquid nitrogen, and stored at $-80^{\circ} \mathrm{C}$ until analysis. Tissues were homogenized in buffer (10 mM Tris, $5 \mathrm{mM}$ EDTA [ethylenediaminetetraacetic acid], 2\% Triton X-100, $0.2 \mathrm{mM} \mathrm{Na}_{3} \mathrm{VO}_{4}, 1 \mathrm{mM}$ phenylmethylsulfonyl fluoride, and $10 \mu \mathrm{g} / \mathrm{ml}$ leupeptin and aprotinin) and mechanically disrupted. Samples were analyzed by SDSPAGE by means of a transfer buffer $(25 \mathrm{mM} / \mathrm{l}$ Tris, $192 \mathrm{mM} / \mathrm{l}$ glycine, and $20 \%$ methanol) in a wet-transfer apparatus. Blots were blocked with 5\% non-fat dry milk in phosphate-buffered saline with $0.1 \%$ Tweens-20 and then incubated with mouse anti-rat monoclonal HSP70 antibody (Sigma-Aldrich). After repeated washing, rabbit anti-mouse secondary antibody (horseradish peroxidase-conjugated) incubation was performed, developed with a chemiluminescence system, and followed with film exposure and relative intensity analysis.

\section{Detection of plasma tumor necrosis factor-alpha, interleukin-6, and malondialdehyde}

The arterial blood sample $(1.5 \mathrm{ml})$ was collected from all groups at 90 minutes (for tumor necrosis factor-alpha [TNF- $\alpha$ ] detection, plasma peak was thought to be achieved within two 
hours after LPS injection [16]) and six hours (for plasma interleukin-6 [IL-6] and malondialdehyde [MDA] detection) after administration of LPS. Blood was then centrifuged for eight minutes at $3,500 \mathrm{~g}$ and $4^{\circ} \mathrm{C}$, and the supernatant was collected. The plasma IL- 6 and TNF- $\alpha$ were analyzed using enzyme-linked immunosorbent assay kits (Shanghai Hua Sen Science \& Technology CO. Ltd., Shanghai, China). Results were then obtained using a microplate reader (Model 680; Bio-Rad Laboratories, Inc, Tokyo, Japan). The content of plasma MDA levels was measured by means of a thibabituric acid reaction.

\section{Statistical analysis}

Concentration-response data were fitted to a sigmoidal maximum efficacy $\left(E_{\max }\right)$ model by means of GraphPad Prism software (GraphPad Software, Inc., San Diego, CA, USA). The values of $P E E_{\max }$ and median effective dose $\left(E C_{50}\right)$ were determined for each treatment group. Data are presented as mean \pm standard deviation. Statistical analyses were performed using one-way analyses of variance. All analysis was performed using the Statistical Software Package (SPSS version 11.5; SPSS Inc., Chicago, IL, USA). Statistical significance was assigned at a $P$ value of less than 0.05 .

\section{Results \\ Changes in mean arterial pressure in response to phenylephrine}

There were no significant differences in baseline levels of MAP among the groups, but MAP decreased to $75 \%$ to $70 \%$ of the baseline level six hours after administration of LPS. PE produced a dose-dependent increase in MAP in all groups, but the maximal percentage increase in MAP significantly decreased to $12.7 \%$ in the LPS shock group $(P<0.05)$ and was restored to $15.6 \%$ in the Ala-Gln+LPS group whereas the maximal percentage increase in the control group was $24.7 \%$ $(P<0.05)$ (Figure 1).

\section{Isolated vascular response to phenylephrine}

In the vascular tension experiments, each tissue developed tension to $\mathrm{PE}$ in a concentration-dependent way. The average values of $P E E_{50}$ and $E_{\max }$ in the control group were $8.55 \pm$ $0.08 \mathrm{nmol} / \mathrm{l}$ and $1.86 \pm 0.05 \mathrm{~g}$, respectively (Table 1). $P E E_{\max }$
Figure 1

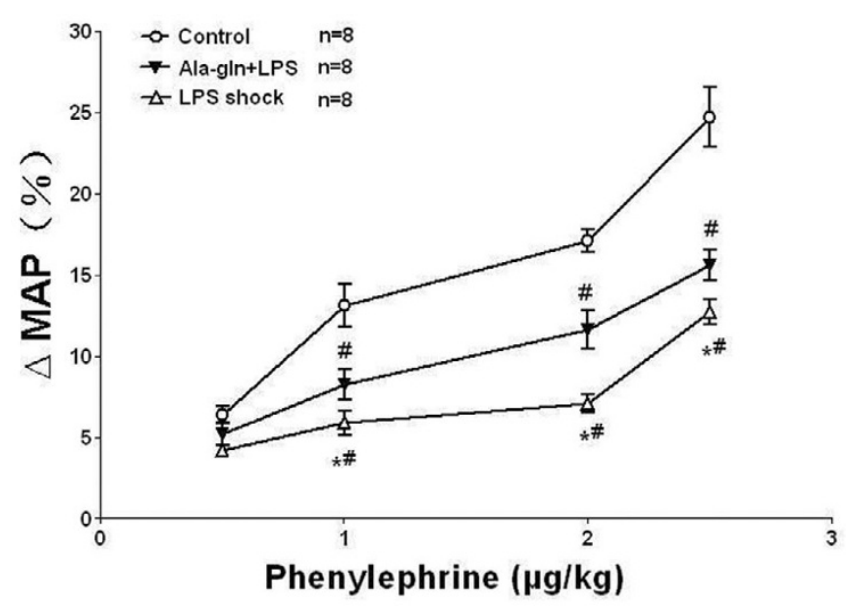

The percentage increase in mean arterial pressure (MAP) induced by phenylephrine in different groups of rats. The maximal percentage increase in MAP significantly decreased to $12.7 \%$ in the LPS shock group $(P<0.05)$ and was restored to $15.6 \%$ in the Ala-Gln+LPS group, whereas the maximum percentage increase in the control group was $24.7 \%$ ( $n=8$, mean \pm standard deviation). ${ }^{*} P<0.05$ versus the Ala-Gln+LPS group; $\# P<0.05$ versus the control group. Ala-Gln+LPS, alanyl-glutamine dipeptide + lipopolysaccharide shock; LPS shock, lipopolysaccharide shock.

significantly decreased to $51 \%(0.95 \pm 0.01 \mathrm{~g})$ in the LPS shock group and was restored to $68 \%(1.27 \pm 0.03 \mathrm{~g})$ in the Ala-Gln+LPS group, whereas PE $E_{\max }$ in the control group was taken as 100\% $(P<0.05)$ (Figure 2, Table 1). Likewise, fitted $\mathrm{PE} \mathrm{EC_{50 }}$ significantly increased to $13.49 \pm 0.06 \mathrm{nmol} / \mathrm{l}$ in the LPS shock group and was reversed to $10.15 \pm 0.04 \mathrm{nmol} / \mathrm{l}$ in the Ala-Gln+LPS group $(P<0.05)$ (Table 1).

\section{Glutamine enhances HSP70 expression}

The analyses from Western blotting showed that HSP70 expressions in heart tissue (Figure 3a), aorta tissue (Figure $3 b$ ), lung tissue (Figure 3c), and liver tissue (Figure 3d) were weak in the control group but markedly stronger in the LPS shock group $(P<0.05)$. The expressions of HSP70 were much higher than those in the LPS shock group from four tissues in the Ala-Gln+LPS group $(P<0.05)$ (Figure 3a-d).

Table 1

The values of $P E E_{\max }$ and $E C_{50}$ on aortic rings in the different groups of rats

\begin{tabular}{lcr}
\hline Group & $E_{\max }(\mathrm{g})$ & $E_{50}(\mathrm{nmol} / \mathrm{l})$ \\
\hline Control & $1.86 \pm 0.04$ & $8.55 \pm 0.08$ \\
LPS shock & $0.95 \pm 0.01^{\mathrm{a}}$ & $13.49 \pm 0.06^{\mathrm{a}}$ \\
Ala-Gln+LPS & $1.27 \pm 0.02^{\mathrm{a}, \mathrm{b}}$ & $10.15 \pm 0.04^{\mathrm{a}, \mathrm{b}}$ \\
\hline
\end{tabular}

Data are shown as mean \pm standard deviation ( $n=8$ in each group). a $P<0.05$ versus the control group; ${ }^{b} P<0.05$ versus the LPS shock group. Ala-Gln+LPS, alanyl-glutamine dipeptide + lipopolysaccharide shock; $E_{\max }$, maximum efficacy; $E_{50}$, median effective dose; LPS, lipopolysaccharide. 
Figure 2

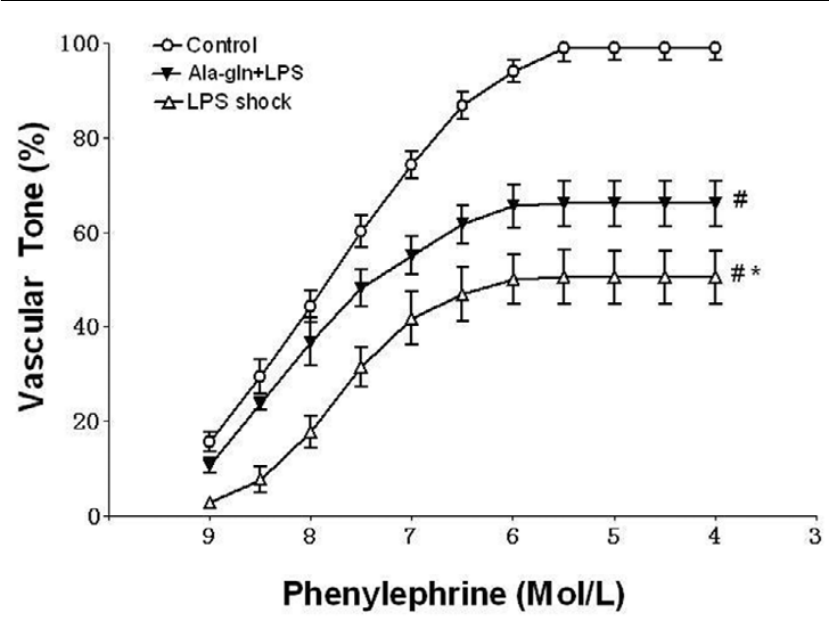

The concentration-response curves of phenylephrine (PE) in aortic rings from different groups of rats (mean \pm standard deviation). PE maximum efficacy $\left(E_{\max }\right)$ significantly decreased to $51 \%$ in the LPS shock group and was restored to $68 \%$ in the Ala-Gln+LPS group $(P<0.05)$, whereas $P E E_{\max }$ in the control group was taken as $100 \%$. ${ }^{*} P<0.05$ versus the Ala-Gln+LPS group. \#P<0.05 versus the control group. Ala-GIn+LPS, alanyl-glutamine dipeptide + lipopolysaccharide shock; LPS shock, lipopolysaccharide shock.

\section{Glutamine decreases plasma concentrations of TNF- $\alpha$, IL-6, and MDA}

The plasma TNF- $\alpha$, IL- 6 , and MDA levels were low in the control group $(49.7 \pm 12.2 \mathrm{pg} / \mathrm{ml}, 23.5 \pm 9.2 \mathrm{pg} / \mathrm{ml}$, and $4.66 \pm$ $0.55 \mathrm{~mol} / \mathrm{ml}$, respectively). They significantly increased in the LPS shock group $(293.1 \pm 52.2 \mathrm{pg} / \mathrm{ml}, 296.2 \pm 60.2 \mathrm{pg} / \mathrm{ml}$, and $9.71 \pm 0.87 \mathrm{~mol} / \mathrm{ml}$, respectively; $P<0.01$ ) (Table 2). Pretreatment with Ala-GIn significantly decreased plasma concentrations of TNF- $\alpha$, IL- 6 , and MDA compared with the LPS shock group (131.8 $\pm 27.7 \mathrm{pg} / \mathrm{ml}, 204.1 \pm 42.2 \mathrm{pg} / \mathrm{ml}$, and $5.89 \pm 0.58 \mathrm{~mol} / \mathrm{ml}$, respectively; $P<0.05$ ) (Table 2 ).

\section{Discussion}

The results of this study demonstrate that pretreatment of AlaGln significantly improved vascular response to catecholamine vasoconstrictors and that the effect of Ala-Gln is associated with its capacity to induce HSP70 expression and attenuate release of pro-inflammatory cytokines and oxidizing species production after septic shock. HSP70 is the most important protein in HSP family to generate a protective effect against injuries in the presence of various stresses [17]. Previous studies in rat models of HSP induction to protect against septic shock have used sodium arsenite or heat as an inducer for the stress response. Sodium arsenite is known to be quite toxic; a previous experiment showed a $20 \%$ mortality rate from the arsenite alone [18]. HSP expression has also been induced by measures that increase core body temperature [19]. However, these measures are clinically impractical because they would be poorly tolerated by patients and would have detrimental effects on many cellular functions [20]. Gln may have therapeutic value in safely and effectively enhancing the expression of HSP and may increase the survival from septic shock [21]. Therefore, we chose Ala-Gln as an HSP expression inducer in this study.

In the present study, we designed pretreatment of $0.75 \mathrm{~g} / \mathrm{kg}$ Gln to be one hour before LPS injection and performed a vascular functional test six hours after administration of LPS. The dose of Gln dipeptide used in this study was based on our previous data, which indicate that the maximal HSP70 mRNA expression in rats occurs at 6 to approximately 12 hours after an intravenous dose of $0.75 \mathrm{~g} / \mathrm{kg}$ Gln. This dose has also been demonstrated to safely induce HSP70 expression in sepsis rats [22]. One limitation of this study seems to be that we chose the pretreatment of Ala-Gln rather than to treat at the onset or after a septic injury since the latter is more likely to get close to the clinical utility. This was done because from our previous experimental data, we know that the maximal HSP70 expression occurs at six hours after Ala-Gln is used. However, administration of LPS results in hypotension at the third to fourth hour in rats [23]. If Gln injection time is same with or post LPS application, maybe could not exactly evaluate the protective effect of Gln on vascular reactivity because Glninduced maximal HSP expression dose not obtained.

A potential limitation of this study is that we chose to use a vehicle-based control rather than an iso-nitrogenous amino acid control. Previous studies have shown that alanine does not lead to significant enhancement of HSP70 either in animals [24] or patients [25], suggesting that the pharmacological effects we have observed are related to the Gln treatment.

Ala-Gln must be diluted five times for intravenous administration based on its description; therefore, there is an excessive amount of fluid infusion in the present study. This acute volume overloading results in slight increases in blood pressure and heart rate but does not lead to death in rats. The effects of volume overloading on the measurement of MAP should be considered. However, the volume of infusion in every administration was strictly controlled according to body weight to be the same in the three groups, and the MAP still decreased after administration of LPS. This indicates that, although volume overloading could temporarily change the hemodynamics in rats, the change of MAP could still be considered a sensitive parameter that reflected vascular response to agonists in the present study. Furthermore, a total of $3 \mathrm{ml}$ of blood was drawn at 90 minutes and 6 hours before the start of the experiment and this may have partially reduced the influence of hypervolemia.

Endotoxin shock is characterized by a marked oxidant stress [26] and a rapid production of different cytokines [27]. Nuclear factor-kappa-B is a transcription factor that plays a central role in the modulation of the inflammatory and immune responses and induces the expression of many genes of inducible nitric oxide synthase, cytokine tissue factor, and 


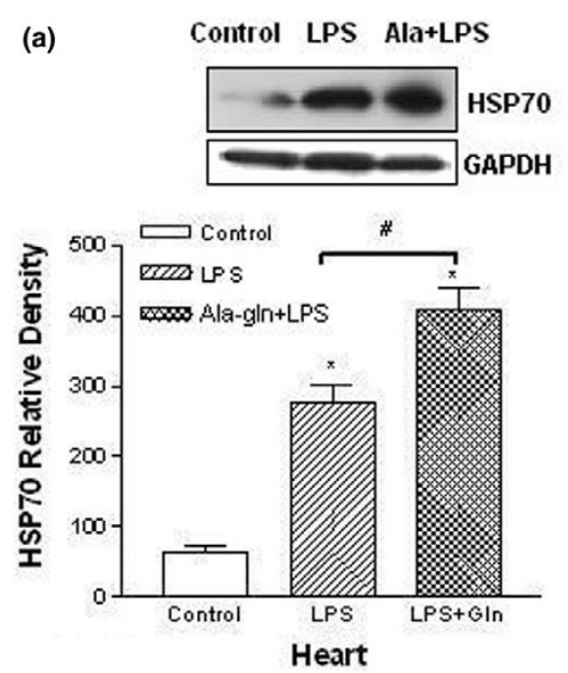

(c)
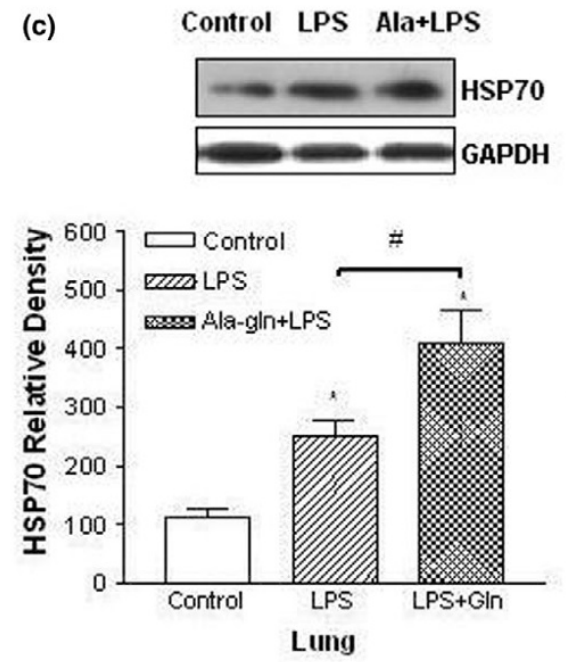
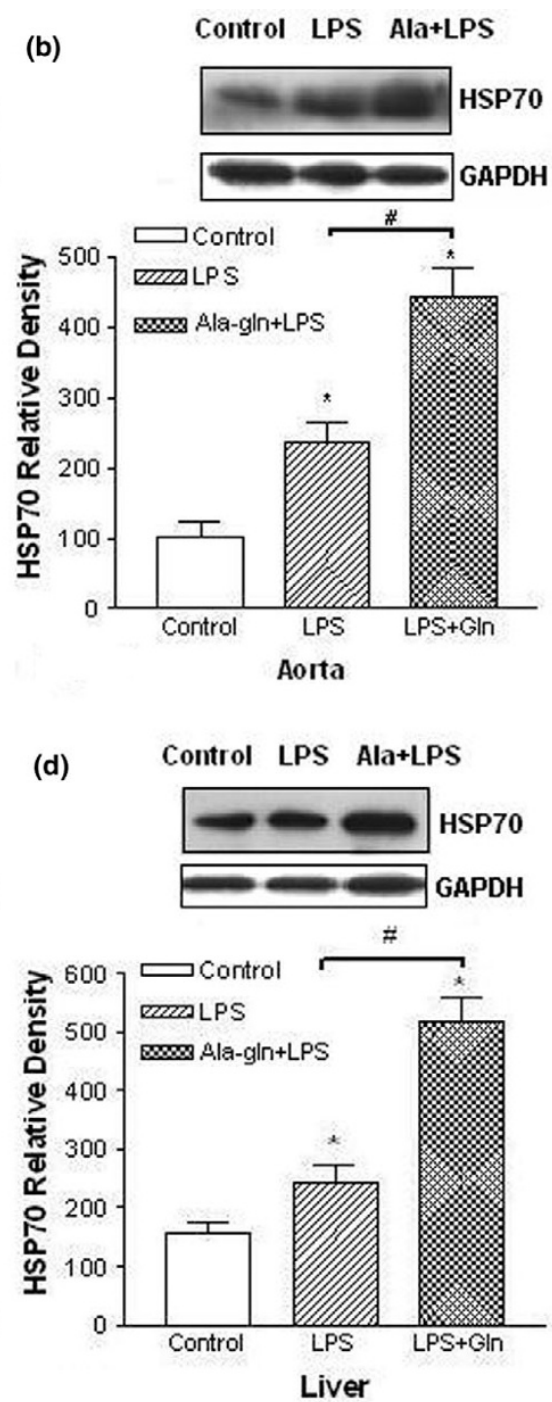

Effects of alanyl-glutamine on heat-shock protein 70 (HSP70) expression in heart, aorta, lung, and liver in endotoxin rats. HSP70 expressions were analyzed by Western blotting analysis. Relative density refers to the ratio of HSP70 to GAPDH. The expression of HSP70 was significantly increased after lipopolysaccharide (LPS) injection compared with the control group in heart (a), aorta (b), lung (c), and liver (d) tissue. ( ${ }^{\star} P<0.05 ; n$ $=5$ ). The expressions of HSP70 were much higher than those in the LPS shock group from four tissues in the Ala-Gln+LPS group (\#P<0.05; $n=$ 5). Ala-Gln+LPS, alanyl-glutamine dipeptide + lipopolysaccharide shock; Ala+LPS, alanyl-glutamine dipeptide + lipopolysaccharide shock; GAPDH, glyceraldehyde-3-phosphate dehydrogenase; LPS+GIn, alanyl-glutamine dipeptide + lipopolysaccharide shock.

adhesion molecules involved in the pathogenesis of endotoxin shock [28]. The results of our study showed that the levels of plasma TNF- $\alpha$, IL-6, and MDA in the Ala-GIn+LPS group were lower than those in the LPS shock group, indicating that the inhibited pro-inflammatory cytokine release and peroxide production may also be attributed to the protective effects of $\mathrm{Gln}$ on LPS-induced vascular hyporeactivity. The mechanism involved may be that GIn inhibits the expression of the inflammatory cytokines directly [22] or that Gln-induced HSP70 expression further enhanced this effect [29].

The data provided in this study demonstrate two discrete mechanistic effects produced by Ala-GIn, namely the reduced
LPS-induced cytokine presence in plasma and the increased HSP70 in multiple tissues. The actual upstream mechanisms responsible for these changes are not clear, but they may be separately regulated and influenced by Ala-Gln. We hypothesize that this dual effect of decreased cytokineinduced vascular injury/action and increased vascular cell survival may be critical for the improved outcomes we observed. Further studies to define the molecular pathways responsible for these discrete actions are clearly warranted, as is further investigation of Gln as a modulator of sepsis-related cardiovascular outcomes. 
Table 2

Plasma concentrations of TNF- $\alpha$, IL-6, and MDA in the different groups of rats

\begin{tabular}{lccc}
\hline Group & TNF- $\alpha(\mathrm{pg} / \mathrm{ml})$ & $\mathrm{IL}-6(\mathrm{pg} / \mathrm{ml})$ & $\mathrm{MDA}(\mathrm{mol} / \mathrm{ml})$ \\
\hline Control & $49.7 \pm 12.2$ & $23.5 \pm 9.2$ & $4.66 \pm 0.55$ \\
LPS shock & $293.1 \pm 52.2^{\mathrm{a}}$ & $296.2 \pm 60.2^{\mathrm{a}}$ & $9.71 \pm 0.87^{\mathrm{a}}$ \\
Ala-Gln+LPS & $131.8 \pm 27.7^{\mathrm{a}, \mathrm{b}}$ & $204.1 \pm 42.2^{\mathrm{a}, \mathrm{b}}$ & $5.89 \pm 0.58^{\mathrm{a}, \mathrm{b}}$ \\
\hline
\end{tabular}

Data are shown as mean \pm standard deviation ( $n=8$ in each group). a $P<0.05$ versus the Ala-Gln+LPS group; ${ }^{b} P<0.05$ versus the control group. Ala-Gln+LPS, alanyl-glutamine dipeptide + lipopolysaccharide shock; IL-6, interleukin-6; LPS, lipopolysaccharide; MDA, malondialdehyde; TNF- $\alpha$, tumor necrosis factor-alpha.

\section{Conclusion}

Gln has been well demonstrated to protect against organ dysfunction in animal experiments and in critically ill patients by inducing HSP70 expression, attenuating sepsis-induced metabolic dysfunction, and reducing inflammatory cytokine release and peroxide production. Here, we further demonstrated that administration of a dose of $0.75 \mathrm{~g} / \mathrm{kg}$ Gln could protect against vascular hyporeactivity in endotoxic shock rats. Thus, Ala-Gln could be used to induce the protective stress response and prevent end-organ injury and possibly decrease mortality from sepsis and improve outcomes in critically ill patients.

Key messages
- Alanyl-glutamine improves vascular hyporeactivity in
endotoxic shock rats.
- The protective role of alanyl-glutamine on vascular reac-
tivity comes from inducing HSP70 expression and
reducing inflammatory cytokine release and peroxide
biosynthesis.
These results suggest that alanyl-glutamine has poten-
tially beneficial therapeutic effects in sepsis.

\section{Competing interests}

The authors declare that they have no competing interests.

\section{Authors' contributions}

$\mathrm{LJ}$ carried out the design of the study, established the experimental setup, drafted the manuscript, and participated in part of the animal experiments. QW carried out the in vivo and in vitro animal experiments and blood analysis and performed the statistical analysis. FW carried out the HSP70 protein expression detection. All authors read and approved the final manuscript.

\section{Acknowledgements}

The authors thank John Anthony Bauer (associate professor at the Division of Pharmacology and director of the Center for Cardiothoracic Research Columbus Children's Research Institute, Columbus, $\mathrm{OH}$, USA) for his critical reading of and comments on the manuscript. This work was supported in part by a Jiangsu Province Key Institution of Anesthesiology Open Foundation grant from the Health Department of Jiangsu Province (Nanjing, China) (no. WK200502) to LJ. This work was presented at the 2006 annual meeting of the American Society of Anesthesiologists, held in Chicago, IL, USA.

\section{References}

1. Glauser MP: Pathophysiologic basis of sepsis: considerations for future strategies of intervention. Crit Care Med 2000, 28(9 Suppl):S4-S8.

2. Sheehan $M$, Wong HR, Hake PW, Zingarelli B: Protective effects of isohelenin, an inhibitor of nuclear factor kappaB, in endotoxic shock in rats. J Endotoxin Res 2002, 8:99-107.

3. Kilbourn R: Nitric oxide synthase inhibitors - a mechanismbased treatment of septic shock. Crit Care Med 1999, 27:857-858

4. Zacharowski K, Berkels R, Olbrich A, Chatterjee PK, Cuzzocrea S, Foster SJ, Thiemermann C: The selective guanylate cyclase inhibitor ODQ reduces multiple organ injury in rodent models of Gram-positive and Gram-negative shock. Crit Care Med 2001, 29:1599-1608.

5. Annane D, Sebille V, Charpentier C, Bollaert PE, Francois B, Korach JM, Capellier G, Cohen Y, Azoulay E, Troche G, et al: Effect of treatment with low doses of hydrocortisone and fludrocortisone on mortality in patients with septic shock. JAMA 2002, 288:862-871.

6. d'Emmanuele di Villa Bianca R, Marzocco S, Di Paola R, Autore G, Pinto A, Cuzzocrea S, Sorrentino R: Melatonin prevents lipopolysaccharide-induced hyporeactivity in rat. J Pineal Res 2004, 36:146-154.

7. Lindquist S, Craig EA: The heat-shock proteins. Annu Rev Genet 1988, 22:631-677.

8. Ang D, Liberek K, Skowyra D, Zylicz M, Georgopoulos C: Biological role and regulation of the universally conserved heat shock proteins. J Biol Chem 1991, 266:24233-24236.

9. Benjamin IJ, McMillan DR: Stress (heat shock) proteins: molecular chaperones in cardiovascular biology and disease. Circ Res 1998, 83:117-132.

10. Huber SA: Heat-shock protein induction in adriamycin and picornavirus-infected cardiocytes. Lab Invest 1992, 67:218-224.

11. Toba T, Shidoji Y, Fujii J, Moriwaki H, Muto Y, Suzuki T, Ohishi N, Yagi K: Growth suppression and induction of heat-shock protein-70 by 9 -cis beta-carotene in cervical dysplasia-derived cells. Life Sci 1997, 61:839-845.

12. Suzuki K, Sawa $Y$, Kaneda $Y$, Ichikawa $H$, Shirakura $R$, Matsuda $H$ : In vivo gene transfection with heat shock protein 70 enhances myocardial tolerance to ischemia-reperfusion injury in rat. $J$ Clin Invest 1997, 99:1645-1650.

13. Wischmeyer PE, Kahana M, Wolfson R, Ren H, Musch MM, Chang EB: Glutamine induces heat shock protein and protects against endotoxin shock in the rat. J Appl Physiol 2001, 90:2403-2410.

14. Singleton KD, Serkova N, Banerjee A, Meng X, Gamboni-Robertson F, Wischmeyer PE: Glutamine attenuates endotoxininduced lung metabolic dysfunction: potential role of enhanced heat shock protein 70. Nutrition 2005, 21:214-223.

15. Fink MP, Heard SO: Laboratory model of sepsis and septic shock. J Surg Res 1990, 49:186-196.

16. Beutler BA, Milsark IW, Cerami A: Cachectin/tumor necrosis factor: production, distribution, and metabolic fate in vivo. $J$ Immunol 1985, 135:3972-3977. 
17. Jaattela M: Heat shock proteins as cellular lifeguards. Ann Med 1999, 31:261-271.

18. Ribeiro SP, Villar J, Downey GP, Edelson JD, Slutsky AS: Sodium arsenite induces heat shock protein-72 kilodalton expression in the lungs and protects rats against sepsis. Crit Care Med 1994, 22:922-929.

19. Chu EK, Ribeiro SP, Slutsky AS: Heat stress increases survival rates in lipopolysaccharide-stimulated rats. Crit Care Med 1997, 25:1727-1732.

20. De Maio A: Heat shock proteins: facts, thoughts, and dreams. Shock 1999, 11:1-12.

21. Singleton KD, Serkova N, Beckey VE, Wischmeyer PE: Glutamine attenuates lung injury and improves survival after sepsis: role of enhanced heat shock protein expression. Crit Care Med 2005, 33:1206-1213.

22. Singleton KD, Beckey VE, Wischmeyer PE: Glutamine prevents activation of NF-kappaB and stress kinase pathways, attenuates inflammatory cytokine release, and prevents acute respiratory distress syndrome (ARDS) following sepsis. Shock 2005, 24:583-589.

23. Szabo C: Alterations in nitric oxide production in various forms of circulatory shock. New Horiz 1995, 3:2-32.

24. Lindemann G, Grohs M, Stange EF, Fellermann K: Limited heatshock protein 72 induction in Caco-2 cells by I-glutamine. Digestion 2001, 64:81-86.

25. Ziegler TR, Ogden LG, Singleton KD, Luo M, Fernandez-Estivariz C, Griffith DP, Galloway JR, Wischmeyer PE: Parenteral glutamine increases serum heat shock protein $\mathbf{7 0}$ in critically ill patients. Intensive Care Med 2005, 31:1079-1786.

26. Altavilla D, Squadrito F, Campo GM, Squadrito G, Arlotta M, Urna G, Sardella A, Quartarone C, Saitta A, Caputi AP: The lazaroid, U74389G, inhibits inducible nitric oxide synthase activity, reverses vascular failure and protects against endotoxin shock. Eur J Pharmacol 1999, 369:49-55.

27. Zuckerman SH, Bryan-Poole N, Evans GF, Short L, Glasebrook $A L$ : In vivo modulation of murine serum tumour necrosis factor and interleukin- 6 levels during endotoxemia by oestrogen agonists and antagonists. Immunology 1995, 86:18-24.

28. Barnes PJ, Karin M: Nuclear factor-kappaB: a pivotal transcription factor in chronic inflammatory diseases. N Engl J Med 1997, 336:1066-1071.

29. Schell MT, Spitzer AL, Johnson JA, Lee D, Harris HW: Heat shock inhibits NF-kB activation in a dose- and time-dependent manner. J Surg Res 2005, 129:90-93. 